\title{
DOES DENTAL STUDENTS' ATTENDANCE IN CLASSROOM LECTURES DEPEND ON THE MODE OF ATTENDANCE TRACKING?
}

\author{
Hani Mawardi ${ }^{1}$ (Corresponding author), \\ Waad Alharbi ${ }^{2}$, Waleed Alamoudi ${ }^{3}$, Osama Felemban $^{4}$, Soulafa Almazrooa ${ }^{5}$, Emad Alhadlag $^{6}$ \\ 1,2,3,4,5 King Abdulaziz University, Faculty of Dentistry, Jeddah, Saudi Arabia \\ ${ }^{6}$ King Saud University, Faculty of Dentistry, Riyadh, Saudi Arabia \\ hmawardi@kau.edu.sa
}

\begin{abstract}
Purpose: The necessity to attend classroom lectures is a disputable topic among dental schools globally. Since there is an ongoing debate on different aspects of this problem in literature, the purpose of this study was to compare students' attitudes toward classroom attendance and investigate if stricter attendance tracking methods could lead to better classroom attendance at two dental schools utilising different modes of tracking students' attendance. Method: This was an observational, cross-sectional survey distributed among dental students enrolled at King Abdul-Aziz University (KAU) and King Saud University (KSU) in Saudi Arabia. The survey included questions on demographics, average travel time, student's attitudes toward classroom lectures and common reasons for absenteeism. Collected data were analysed and summarised as frequencies and percentages and then compared using the Chi-square test for statistical significance.

Findings: The study involved 678 participants from KAU and 475 participants from KSU. In general, there was a significant difference in students' attendance between both schools in which $26.8 \%$ of KAU dental students skipped 5 or more lectures/month compared to $11.5 \%$ of students at KSU. Among the factors affecting classroom lecture attendance, commuting time was a major one reported by students $(44.8 \%$ of students at KSU and $51.4 \%$ at KAU needed $30-60$ min to reach their schools). The availability of lectures through online resources and the necessity to study for exams were additional factors reported by students of both schools. Implications for research and practices: Based on the current data, the school's method to track students' attendance may have a role in the pattern of classroom absenteeism.
\end{abstract}

Keywords: dental students; attendance; lectures; classroom; tracking; absenteeism.

\section{Introduction}

The necessity to attend in-class lectures has been a controversial topic among dental educators triggered by the change in dental students' generational change and attitudes combined with the recent schools' investments and shift toward virtual learning during the time of COVID-19 outbreak (Stewart, Stott, \& Nuttall, 2011). Student' absenteeism patterns vary between dental institutes with no official data or literature to assess the magnitude of this phenomenon and its impact on dental education (Desalegn, Berhan, \& Berhan, 2014). Factors such as the school adopted curriculum, lecturer's attitude, students' lack of motivation or interest towards specific subject have been linked to classroom absence reported in the medical literature (Alhabi et al., 2017; Moore, Armstrong, \& Pearson, 2008). In the study by Waleed et al. (unpublished data), the experience of a single dental school was reported which showed that daily travel time and early morning classes are the two major reasons for dental students to skip classroom lectures. Several recommendations were suggested to address this issue which included modifications to the academic timetable, improvement of educators' presentation skills and wider implementation of technological advancement in teaching (Alhabi, 2017; Cook, 2005).

As of today, many dental schools continue to mandate students' traditional presence in-class. However, implementing optional attendance can also be viewed as a possible alternative. On the one hand, a more flexible students` attendance policy could have a negative effect on the educational process with the compromised learning experience, lack of in-class interactive discussions and use of educational resources posing an impact on the overall academic performance (Massingham P, 2006). On the other hand, due to a steady increase in a number of accepted students annually in a single class internationally, optional attendance may help to decrease the student/lecturer ratio in classrooms. Portals for distant learning with video recordings of lectures can provide an access to them at a later time. This option may work best as a coping tool for students with psychological challenges such as social anxiety and for those who spend much time commuting to university. However, educators in health-related specialities, including dentistry, are likely to support physical attendance of

(C) Hani Mawardi, Waad Alharbi, Waleed Alamoudi, Osama Felemban, Soulafa Almazrooa, Emad Alhadlag. 2021. Published by Igor Sikorsky Kyiv Polytechnic Institute. This is an Open Access article distributed under the terms of the licence CC BY 4.0 
professional courses and group discussions to ensure the achievement of the required levels of professional competencies by students.

In view of the lack of studies on dental students' attendance compliance and attitudes, the purpose of this study was to compare students' attitudes toward classroom attendance and investigate if stricter attendance tracking methods could lead to better classroom attendance at two dental schools utilising different modes of tracking students' attendance. We believe the outcome of this study will be a great addition to the literature and facilitate the advancement of dental education.

\section{Material and methods}

A human research ethical approval was obtained from King Abdul-Aziz University (KAU) Faculty of Dentistry and King Saud University (KSU) College of Dentistry. The selection of both KAU and KSU dental schools to participate in this survey was based on curriculum similarity, difference in their student attendance tracking mechanisms and a large number of active students to ensure diversity of participants. For instance, tracking of students' attendance at KAU is conducted manually during the classroom lectures, however, KSU has adapted a stricter daily tracking method using fingerprints. In addition, both schools maintain separate classes for male and female students in which the same lecture is given twice at different times.

This was designed as an observational, cross-sectional survey among the students of all 5 years of study of both dental schools (excluding the first pre-dental year and mandatory internship year because of differences in structure between the two schools) to assess students' attitudes toward classroom attendance starting from January 2018. Most of the included questions were based on the assigned didactic curriculum for each year of study, i.e.: gross anatomy, biochemistry, histology and embryology, dental anatomy, biomaterials (2nd year); operative and restorative dentistry, biomaterials, microbiology, oral histology, oral pathology, oral radiology, general pathology, pharmacology, pain control ( $3^{\text {rd }}$ year); operative and restorative dentistry, endodontics, general medicine, oral biology, periodontics, oral radiology, removable and fixed prosthodontics, ethics and law, biostatistics, general surgery $\left(4^{\text {th }}\right.$ year); operative and restorative dentistry, endodontics, periodontics, oral medicine, oral surgery, removable and fixed prosthodontics, pedodontics, orthodontics, pharmacology $\left(5^{\text {th }}\right.$ year); oral surgery, pedodontics, orthodontics (6th year).

The survey was an adopted variant of Alamoudi et al. (2016) with minimal modifications to match the present study population and distributed by study co-investigators in person among the enrolled students in all 5 years of study at KAU and KSU. Each participating student was asked to fill in the questionnaire containing 13 questions divided into 4 sections. The survey included questions on demographics and students' attitudes towards classroom lectures. Additionally, the participants of the study were asked to rank the 3 top reasons behind skipping classroom lectures in addition to ranking the subjects according to the likelihood of lecture absenteeism and tardiness.

Students' responses were summarised as frequencies and percentages. In addition, collected data were compared by gender, academic year, and average GPA using Chi-square test with a significance level set at 0.05 . Statistical analysis was carried over using IBM SPSS Statistics for Windows, Version 23.0.

\section{Results}

\section{Demographics of respondents}

The study was structured following the STROBE initiative on reporting observational studies (von Elm et al., 2008). A total of 678 dental students at KAU and 475 dental students at KSU participated and completed the survey. The KAU data was previously reported and will only be compared to KSU data in this study. All demographics of participating students can be found in Table 1.

Table 1. Demographics of participating students from KAU and KSU

\begin{tabular}{|c|c|c|c|c|}
\hline & Categories & $\begin{array}{c}\text { KAU } \\
n=678\end{array}$ & $\begin{array}{c}\text { KSU } \\
n=475\end{array}$ & $p$-value \\
\hline & & $\mathrm{n}(\%)$ & $\mathrm{n}(\%)$ & \\
\hline \multirow[t]{2}{*}{ Gender } & Male & $299(44.1)$ & $265(55.8)$ & \multirow[t]{2}{*}{$<0.001$} \\
\hline & Female & $379(55.9)$ & $210(44.2)$ & \\
\hline
\end{tabular}




\begin{tabular}{|c|c|c|c|c|}
\hline \multirow[t]{2}{*}{ Marital Status } & Single & 652 (96.6) & 470 (98.9) & \multirow[t]{2}{*}{0.011} \\
\hline & Married & $23(3.4)$ & $5(1.1)$ & \\
\hline \multirow[t]{2}{*}{ Number of Children } & None & $661(98.4)$ & $474(99.8)$ & \multirow[t]{2}{*}{0.019} \\
\hline & One or more & $11(1.6)$ & $1(0.2)$ & \\
\hline \multirow[t]{5}{*}{ Academic Year } & $1^{\text {st }}$ & $180(26.6)$ & $121(25.5)$ & \multirow[t]{5}{*}{0.091} \\
\hline & $2^{\text {nd }}$ & $125(18.5)$ & $110(23.3)$ & \\
\hline & $3^{\text {rd }}$ & $90(13.3)$ & $61(12.8)$ & \\
\hline & $4^{\text {th }}$ & $169(25.0)$ & $92(19.4)$ & \\
\hline & $5^{\text {th }}$ & $113(16.7)$ & $91(19.2)$ & \\
\hline \multirow[t]{3}{*}{ Average GPA } & $2.75-3.74$ & $47(6.9)$ & $9(1.9)$ & \multirow[t]{3}{*}{$<0.001$} \\
\hline & $3.75-4.49$ & $251(37.6)$ & $142(30.1)$ & \\
\hline & $4.50-5.00$ & $371(55.5)$ & $321(68.0)$ & \\
\hline
\end{tabular}

\section{Students' attitude towards classroom attendance at $\mathrm{KSU}$}

In order to understand the prevalence of students' absenteeism, study participants at KSU were first asked about their likelihood to skip a classroom lecture. Overall, $60.0 \%$ of students $(285 / 475)$ were more likely to skip 0-2 lectures, $28.6 \%$ (136/475) would skip 3-4 lectures, and 11.4\% (54/475) would skip 5 or more lectures/month. Among all years of study, $2^{\text {nd }}$ year students were the most likely to skip 5 or more lectures/month $(18 / 110$ $(18.2 \%))$ and $3^{\text {rd }}$ year students were the least likely to skip lectures in general $(1 / 61(1.6 \%))$. As for gender, $71.5 \%$ of female students $(149 / 210)$ were likely to skip classroom lectures once or twice/month compared to $51.3 \%(136 / 265)$ of male students. At the same time, $8.3 \%$ of male students $(22 / 265)$ were likely to skip more than 6 classroom lectures/month compared to 1.9\% of female students (4/210) (Table 2).

When asked about the number of times they were late to classroom lectures, almost half of the students were more likely to be late $0-2$ times/month (235/475 (49.5\%)), followed by $3-4$ times/month (126/475 (26.5\%)), 5-6 times/month (48/475 (10.1\%)) and more than 6 times/month (66/475 (13.9\%)). When asked about an option for classroom lectures to be streamed live or recorded and made available at a later time, 39\% of students (188/475) were more likely to skip classroom lectures and utilise this option, while, $23 \%$ of students (113/475) expressed interest in attending classroom lectures even if they were available online and $36 \%$ of students (174/475) had no preference.

Of all participants, $81.7 \%$ (388/475) of students preferred classroom attendance to be non-compulsory. This was more evident in $1^{\text {st }}$ and $2^{\text {nd }}$ year students $(106 / 121(87.6 \%)$ and $89 / 110(89.1 \%)$ respectively). The majority of respondents $(307 / 475(64.6 \%))$ agreed that attending classroom lectures would have a positive impact on their academic progress and $70.5 \%$ of female students (148/210) strongly believed in its positive correlation with the overall GPA (Table 2). To investigate if travel time contributes to students' absenteeism, study participants were asked about their commuting time. In total, $44.4 \%$ of students (211/475) needed less than 30 minutes and $44.8 \%$ (213/475) needed between 30-60 minutes on average to reach their dental schools.

\section{Factors influencing students' attendance in classrooms at KSU}

To better understand the reasons behind students' tendency to attend or skip a classroom lecture, each participant was asked to list the top three factors to influence his/her decision (Table 3). The time of the lecture, specifically early morning, was reported as the most influencing factor to skip a class (260/475 (54.7\%)). This was more evident among male students (180/ 265 (67.9\%)) than among female students (80/210 (38.1\%)). Classroom lectures taking place during exam weeks were reported as the $2^{\text {nd }}$ reason which negatively impacts student attendance $(245 / 475(51.6 \%))$. This tendency was more pronounced in weaker students $(6 / 9(66.7 \%))$ and high achievers (177/321 (55.1\%)) compared to average students (61/142 (43\%)) with GPA range from 3.75 to 4.49. Faculty teaching skills came third (224/475 (47.2\%)) in terms of influence on students' attendance. This was more evident in female (126/210 (60\%)) than in male students $(98 / 256(37 \%))$. 
Table 2. Students' attitude towards classroom lectures attendance at KSU

\begin{tabular}{|c|c|c|c|c|c|c|c|c|c|c|c|c|}
\hline \multirow{2}{*}{\multicolumn{2}{|c|}{ Question }} & \multirow{3}{*}{$\begin{array}{c}\text { Total } \\
\mathrm{n}=475 \\
\end{array}$} & \multirow{2}{*}{\multicolumn{2}{|c|}{ Gender }} & \multirow{2}{*}{\multicolumn{5}{|c|}{ Academic year }} & \multirow{2}{*}{\multicolumn{3}{|c|}{ Average GPA }} \\
\hline & & & & & & & & & & & & \\
\hline & & & $\mathrm{n}=265$ & $n=210$ & $n=121$ & $n=110$ & $\mathrm{n}=61$ & $n=92$ & $\mathrm{n}=91$ & $\mathrm{n}=9$ & $n=142$ & $\mathrm{n}=321$ \\
\hline \multirow{4}{*}{$\begin{array}{l}\text { On average, what } \\
\text { is your commuting } \\
\text { time to school? }\end{array}$} & $<30 \min$ & $211(44.4)$ & $103(38.9)$ & $108(51.4)$ & $55(45.5)$ & $53(48.2)$ & $30(49.2)$ & $37(40.2)$ & $36(39.6)$ & $4(44.4)$ & $52(36.6)$ & $155(48.3)$ \\
\hline & $30-60 \mathrm{~min}$ & $213(44.8)$ & $129(48.7)$ & $84(40.0)$ & $51(42.1)$ & 48 (43.6) & $27(44.3)$ & $39(42.4)$ & $48(52.7)$ & $3(33.3)$ & $77(54.2)$ & $130(40.5)$ \\
\hline & $>60 \min$ & $51(10.7)$ & $33(12.5)$ & $18(8.6)$ & $15(12.4)$ & $9(8.2)$ & $4(6.6)$ & $16(17.4)$ & $7(7.7)$ & $2(22.2)$ & $13(9.2)$ & $36(11.2)$ \\
\hline & \multicolumn{2}{|c|}{$\mathrm{p}$-value } & \multicolumn{2}{|c|}{0.021} & \multicolumn{5}{|c|}{0.285} & \multicolumn{3}{|c|}{0.063} \\
\hline \multirow{2}{*}{$\begin{array}{c}\text { Do you think } \\
\text { attending } \\
\text { classroom lectures } \\
\text { should be optional } \\
\text { for students? }\end{array}$} & Yes & $388(81.7)$ & 209 (78.9) & $179(85.2)$ & $106(87.6)$ & $98(89.1)$ & $44(72.1)$ & $78(84.8)$ & $62(68.1)$ & $7(77.8)$ & $108(76.1)$ & $271(84.4)$ \\
\hline & \multicolumn{2}{|c|}{$\mathrm{p}$-value } & \multicolumn{2}{|c|}{0.071} & \multicolumn{5}{|c|}{$<0.001$} & \multicolumn{3}{|c|}{0.094} \\
\hline \multirow{2}{*}{$\begin{array}{c}\text { Do you think } \\
\text { attending } \\
\text { classroom lectures } \\
\text { have a positive } \\
\text { influence on } \\
\text { students' academic } \\
\text { performance? }\end{array}$} & Yes & 307 (64.6) & $159(60.0)$ & $148(70.5)$ & $74(61.2)$ & $56(50.9)$ & $53(86.9)$ & $60(65.2)$ & $64(70.3)$ & $6(66.7)$ & $97(68.3)$ & $202(62.9)$ \\
\hline & \multicolumn{2}{|c|}{ p-value } & \multicolumn{2}{|c|}{0.018} & \multicolumn{5}{|c|}{$<0.001$} & \multicolumn{3}{|c|}{0.532} \\
\hline \multirow{5}{*}{$\begin{array}{l}\text { How many times } \\
\text { per month on } \\
\text { average do you } \\
\text { skip classes? }\end{array}$} & $0-2$ times & $285(60.0)$ & $136(51.3)$ & $149(71.0)$ & $61(50.4)$ & $57(51.8)$ & $49(80.3)$ & $58(63.0)$ & $60(65.9)$ & $5(55.6)$ & $75(52.8)$ & $202(62.9)$ \\
\hline & 3-4 times & $136(28.6)$ & 89 (33.6) & $47(22.4)$ & $42(34.7)$ & $33(30.0)$ & $11(18.0)$ & $24(26.1)$ & $26(28.6)$ & $2(22.2)$ & $50(35.2)$ & $84(26.2)$ \\
\hline & 5-6 times & $28(5.9)$ & $18(6.8)$ & $10(4.8)$ & $7(5.8)$ & $10(9.1)$ & $0(0.0)$ & $8(8.7)$ & $3(3.3)$ & $1(11.1)$ & $9(6.3)$ & $18(5.6)$ \\
\hline & $>6$ times & $26(5.5)$ & $22(8.3)$ & $4(1.9)$ & $11(9.1)$ & $10(9.1)$ & 1 (1.6) & $2(2.2)$ & $2(2.2)$ & $1(11.1)$ & $8(5.6)$ & $17(5.3)$ \\
\hline & \multicolumn{2}{|c|}{ p-value } & \multicolumn{2}{|c|}{$<0.001$} & \multicolumn{5}{|c|}{0.002} & \multicolumn{3}{|c|}{0.459} \\
\hline \multirow{5}{*}{$\begin{array}{l}\text { How many times } \\
\text { per month on } \\
\text { average are you } \\
\text { late to classes? }\end{array}$} & $0-2$ times & $235(49.5)$ & $104(39.2)$ & $131(62.4)$ & $76(62.8)$ & $50(45.5)$ & $37(60.7)$ & $32(34.8)$ & $40(44.0)$ & $4(44.4)$ & $57(40.1)$ & $173(53.9)$ \\
\hline & 3-4 times & $126(26.5)$ & $75(28.3)$ & $51(24.3)$ & $27(22.3)$ & $30(27.3)$ & $12(19.7)$ & $27(29.3)$ & $30(33.0)$ & $2(22.2)$ & $42(29.6)$ & $82(25.5)$ \\
\hline & 5-6 times & $48(10.1)$ & $37(14.0)$ & $11(5.2)$ & $8(6.6)$ & $10(9.1)$ & $6(9.8)$ & $11(12.0)$ & $13(14.3)$ & $0(0.0)$ & $17(12.0)$ & $30(9.3)$ \\
\hline & $>6$ times & $66(13.9)$ & 49 (18.5) & $17(8.1)$ & $10(8.3)$ & $20(18.2)$ & $6(9.8)$ & $22(23.9)$ & $8(8.8)$ & $3(33.3)$ & $26(18.3)$ & $36(11.2)$ \\
\hline & \multicolumn{2}{|c|}{ p-value } & \multicolumn{2}{|c|}{$<0.001$} & \multicolumn{5}{|c|}{0.002} & \multicolumn{3}{|c|}{0.057} \\
\hline $\begin{array}{l}\text { How do you feel if } \\
\text { the school to }\end{array}$ & $\begin{array}{l}\text { Less likely to } \\
\text { skip or be late } \\
\text { to a lecture }\end{array}$ & $113(23.8)$ & $87(32.8)$ & $26(12.4)$ & $36(29.8)$ & $35(31.8)$ & $6(9.8)$ & $16(17.4)$ & $20(22.0)$ & $4(44.4)$ & $38(26.8)$ & $69(21.5)$ \\
\hline provided video & No difference & $174(36.6)$ & $86(32.5)$ & 88 (41.9) & $41(33.9)$ & $40(36.4)$ & $21(34.4)$ & $36(39.1)$ & $36(39.6)$ & $3(33.3)$ & $54(38.0)$ & $116(36.1)$ \\
\hline $\begin{array}{l}\text { recording of } \\
\text { lectures and make } \\
\text { it available for all }\end{array}$ & $\begin{array}{c}\text { More likely to } \\
\text { skip or be late } \\
\text { to a lecture }\end{array}$ & $188(39.6)$ & $92(34.7)$ & $96(45.7)$ & $44(36.4)$ & $35(31.8)$ & $34(55.7)$ & $40(43.5)$ & $35(38.5)$ & $2(22.2)$ & $50(35.2)$ & $136(42.4)$ \\
\hline & $\mathrm{p}-\mathrm{v}$ & & & & & & 0.017 & & & & 0.290 & \\
\hline
\end{tabular}


Table 3. Factors influencing students' attendance in classroom lectures at KSU

\begin{tabular}{|c|c|c|c|c|c|c|c|c|c|c|c|}
\hline & \multirow[t]{2}{*}{ Total } & \multicolumn{2}{|c|}{ Gender } & \multicolumn{5}{|c|}{ Academic year } & \multicolumn{3}{|c|}{ Average GPA } \\
\hline & & Male & Female & $1 \mathrm{st}$ & 2nd & 3rd & 4th & 5 th & $<3.75$ & $3.75-4.49$ & $\begin{array}{l}4.50- \\
5.00\end{array}$ \\
\hline & $\begin{array}{l}\mathrm{n}=475 \\
(\%)\end{array}$ & $\begin{array}{l}\mathrm{n}=265 \\
(\%)\end{array}$ & $\begin{array}{l}\mathrm{n}=210 \\
(\%)\end{array}$ & $\begin{array}{c}\mathrm{n}=121 \\
(\%)\end{array}$ & $\begin{array}{c}\mathrm{n}=110 \\
(\%)\end{array}$ & $\begin{array}{c}\mathrm{n}=61 \\
(\%)\end{array}$ & $\begin{array}{c}\mathrm{n}=92 \\
(\%)\end{array}$ & $\begin{array}{c}\mathrm{n}=91 \\
(\%)\end{array}$ & $\begin{array}{l}\mathrm{n}=9 \\
(\%)\end{array}$ & $\begin{array}{c}\mathrm{n}=142 \\
(\%)\end{array}$ & $\begin{array}{c}\mathrm{n}=32 \\
1 \\
(\%)\end{array}$ \\
\hline \multirow[t]{2}{*}{$\begin{array}{l}\text { The lecture is before or after } \\
\text { an exam }\end{array}$} & 245 (51.6) & $107(40.4)$ & $138(65.7)$ & $\begin{array}{c}73 \\
(60.3) \\
\end{array}$ & $51(46.4)$ & $38(62.3)$ & 43 (46.7) & $40(44.0)$ & $6(66.7)$ & $61(43.0)$ & $\begin{array}{c}177 \\
(55.1) \\
\end{array}$ \\
\hline & p-value & \multicolumn{2}{|c|}{$<0.001$} & \multicolumn{5}{|c|}{0.030} & \multicolumn{3}{|c|}{0.036} \\
\hline \multirow[t]{2}{*}{$\begin{array}{l}\text { Early morning class } \\
\text { (8-9 am) }\end{array}$} & $260(54.7)$ & $180(67.9)$ & $80(38.1)$ & $\begin{array}{c}55 \\
(45.5)\end{array}$ & 69 (62.7) & $29(47.5)$ & $50(54.3)$ & 57 (62.6) & $7(77.8)$ & 85 (59.9) & $\begin{array}{c}166 \\
(51.7)\end{array}$ \\
\hline & p-value & \multicolumn{2}{|c|}{$<0.001$} & \multicolumn{5}{|c|}{0.031} & \multicolumn{3}{|c|}{0.100} \\
\hline \multirow[t]{2}{*}{ Late day class (3-5 pm) } & 53 (11.2) & $39(14.7)$ & $14(6.7)$ & $\begin{array}{c}23 \\
(19.0)\end{array}$ & $18(16.4)$ & $2(3.3)$ & $5(5.4)$ & $5(5.5)$ & $3(33.3)$ & $12(8.5)$ & $\begin{array}{c}38 \\
(11.8)\end{array}$ \\
\hline & p-value & \multicolumn{2}{|c|}{0.006} & \multicolumn{5}{|c|}{$<0.001$} & \multicolumn{3}{|c|}{0.060} \\
\hline \multirow[t]{2}{*}{$\begin{array}{l}\text { There is more than } 2 \text { hours } \\
\text { break before or after a class }\end{array}$} & 98 (20.6) & $64(24.2)$ & 34 (16.2) & $\begin{array}{c}37 \\
(30.6)\end{array}$ & $16(14.5)$ & $8(13.1)$ & $16(17.4)$ & $21(23.1)$ & $3(33.3)$ & 31 (21.8) & $\begin{array}{c}64 \\
(19.9)\end{array}$ \\
\hline & p-value & \multicolumn{2}{|c|}{0.033} & \multicolumn{5}{|c|}{0.012} & \multicolumn{3}{|c|}{0.578} \\
\hline \multirow[t]{2}{*}{$\begin{array}{l}\text { Video recording of lecture } \\
\text { material is available }\end{array}$} & $44(9.3)$ & $21(7.9)$ & $23(11.0)$ & $\begin{array}{c}8 \\
(6.6)\end{array}$ & $9(8.2)$ & $8(13.1)$ & $11(12.0)$ & $8(8.8)$ & $2(22.2)$ & $12(8.5)$ & $\begin{array}{c}30 \\
(9.3)\end{array}$ \\
\hline & p-value & \multicolumn{2}{|c|}{0.258} & \multicolumn{5}{|c|}{0.548} & \multicolumn{3}{|c|}{0.387} \\
\hline \multirow{2}{*}{$\begin{array}{l}\text { The lecturer's teaching } \\
\text { skills are below } \\
\text { expectations (e.g. reads } \\
\text { directly from slides, lacks } \\
\text { clarity and organisation) }\end{array}$} & $224(47.2)$ & 98 (37.0) & $126(60.0)$ & $\begin{array}{c}46 \\
(38.0) \\
\end{array}$ & $53(48.2)$ & $38(62.3)$ & $38(41.3)$ & $49(53.8)$ & $2(22.2)$ & $52(36.6)$ & $\begin{array}{c}169 \\
(52.6) \\
\end{array}$ \\
\hline & p-value & \multicolumn{2}{|c|}{$<0.001$} & \multicolumn{5}{|c|}{0.013} & \multicolumn{3}{|c|}{0.002} \\
\hline \multirow[t]{2}{*}{$\begin{array}{l}\text { The lecturer is not strict } \\
\text { about student attendance }\end{array}$} & $40(8.4)$ & $14(5.3)$ & $26(12.4)$ & $\begin{array}{c}5 \\
(4.1)\end{array}$ & $11(10.0)$ & $8(13.1)$ & $9(9.8)$ & $7(7.7)$ & $0(0.0)$ & $15(10.6)$ & $\begin{array}{c}25 \\
(7.8)\end{array}$ \\
\hline & p-value & \multicolumn{2}{|c|}{0.006} & & & 0.261 & & & & 0.401 & \\
\hline $\begin{array}{l}\text { The students are not } \\
\text { interested in a topic }\end{array}$ & 95 (20.0) & 46 (17.4) & $49(23.3)$ & $\begin{array}{c}16 \\
(13.2)\end{array}$ & $18(16.4)$ & 15 (24.6) & 18 (19.6) & $28(30.8)$ & $1(11.1)$ & $24(16.9)$ & $\begin{array}{c}70 \\
(21.8)\end{array}$ \\
\hline & p-value & & & & & 0.019 & & & & 0.380 & \\
\hline $\begin{array}{l}\text { The students can learn more } \\
\text { efficiently at home }\end{array}$ & $157(33.1)$ & $72(27.2)$ & $85(40.5)$ & $\begin{array}{c}24 \\
(19.8)\end{array}$ & 49 (44.5) & $21(34.4)$ & $32(34.8)$ & $31(34.1)$ & $2(22.2)$ & 42 (29.6) & $\begin{array}{c}112 \\
(34.9) \\
\end{array}$ \\
\hline & $\mathrm{p}$-value & & & & & 0.003 & & & & 0.418 & \\
\hline $\begin{array}{l}\text { It is difficult for a student to } \\
\text { wake up early }\end{array}$ & $57(12.0)$ & 43 (16.2) & $14(6.7)$ & $\begin{array}{c}11 \\
(9.1)\end{array}$ & 15 (13.6) & (11.5) & $14(15.2)$ & $10(11.0)$ & $0(0.0)$ & 28 (19.7) & $\begin{array}{c}29 \\
(9.0)\end{array}$ \\
\hline & $\mathrm{p}$-value & & & & & 0.689 & & & & 0.003 & \\
\hline $\begin{array}{l}\text { Students have difficulty } \\
\text { with transportation to school }\end{array}$ & $72(15.2)$ & 45 (17.0) & 27 (12.9) & $\begin{array}{c}15 \\
(12.4)\end{array}$ & $16(14.5)$ & $6(9.8)$ & 19 (20.7) & $16(17.6)$ & $0(0.0)$ & 27 (19.0) & $\begin{array}{c}44 \\
(13.7)\end{array}$ \\
\hline & $\mathrm{p}$-value & & & & & 0.323 & & & & 0.150 & \\
\hline $\begin{array}{c}\text { Students do not think } \\
\text { attending classroom lectures }\end{array}$ & $115(24.2)$ & 55 (20.8) & $60(28.6)$ & $\begin{array}{c}25 \\
(20.7)\end{array}$ & 38 (34.5) & $14(23.0)$ & $22(23.9)$ & $16(17.6)$ & $1(11.1)$ & $30(21.1)$ & $\begin{array}{c}83 \\
(25.9) \\
\end{array}$ \\
\hline benefits them & p-value & & & & & 0.050 & & & & 0.358 & \\
\hline
\end{tabular}


Students at each level were asked to identify the top 3 subjects which are more likely to be skipped. The $1^{\text {st }}$ year students reported the combination of anatomy, histology and embryology (67/121 (55.4\%)) followed by biochemistry $(63 / 121(52.1 \%))$ and general physiology (42/121 (34\%)). The top 3 subjects most likely to be skipped by the students of the 2nd year were general microbiology and immunology (43/110 (39.1\%)) followed by dental pharmacology $(37 / 110(33.6 \%))$ and dental material sciences $(35 / 110(31.8 \%))$. For $3^{\text {rd }}$ year students, clinical periodontology came first $(16 / 61(26.2 \%))$ followed by professional ethics $(15 / 61$ $(24.6 \%))$ and pre-clinical pediatric dentistry $(6 / 61(9.8 \%))$. In the $4^{\text {th }}$ year, the subjects which were most likely to be skipped were internal medicine (44/92 (47.8\%)), microbiology (42/92 (45.7\%)), and ear-throat and nose $(42 / 92(45.7 \%))$. Finally, the $5^{\text {th }}$ year students reported biostatistics in dentistry $(44 / 91 ; 48.4 \%)$, followed by dental pharmacology $(16 / 91 ; 17.8 \%)$ and dental public health and community dentistry $(9 / 91$; 9.9\%).

\section{Comparing KAU to KSU data}

The collected data from students at both KAU with KSU were compared to better understand if the implemented method for students' attendance tracking has an impact on overall students' attitude toward attending classroom lectures. In general, no statistically significant differences were noted between KAU and KSU in terms of students' marital status or a number of children. However, there were more male students responses at KAU in comparison to KSU; and more students with a GPA of $>4.5 / 5$ at KSU compared to KAU $(68.0 \%$ vs $55.5 \%$; P $<0.001)$. On average, $60.0 \%$ of KSU students $(285 / 475)$ would skip classroom lectures 0-2 times/month compared to $44.5 \%$ at KAU (298/671), which was statistically significant $(\mathrm{P}<0.001)$ (Figure 1). However, $44.90 \%$ of KAU students were likely to skip 3-6 lectures/month compared to $36.60 \%$ of KSU students. 55.3\% of female students at KAU (208/379) skipped 0-2 classes /month compared to $71.2 \%$ of female students at KSU (149/210). At the same time, $14.4 \%$ of female students at KAU (54/379) missed more than 5 classes/month compared to $6.7 \%$ of female students at KSU (14/210). In total, 39.4\% of male students at KAU skipped 5 or more classes/ month (116/299) compared to 15\% (40/256) at KSU.

Comparing factors affecting student attendance among KAU and KSU, several differences were noted (Figure 2). Commuting time was one factor of major impact as $44.8 \%$ (213/475) of students at KSU needed 30-60 min and $10.7 \%$ (51/475) needed more than 60 minutes to reach the dental school. However, 51.4\% (343/678) of students at KAU required 30-60 min and 16.8\% (112/678) required more than 60 minutes. The availability of recorded lectures online was more attractive to KSU students in general as $39.6 \%$ of students expressed their intention to skip or be late for a classroom lecture compared to $48.4 \%$ of KAU students (312/678). Studying for exams came 2nd for 51.6\% of KSU students (245/475) as a reason to skip classroom lectures compared to $42.9 \%$ of KAU students (291/678). In addition, early morning lectures were reported as a major factor for student absenteeism at both KAU and KSU (353/678 (52.1\%) and 215/475 (45.3\%), respectively). However, $88.8 \%$ (422/475) of KSU students are more likely to attend late-day classroom lectures compared to $31.4 \%$ (213/678) of KAU students. The lecturer's personality and lecturing skills were similarly reported as factors to influence students' attendance; however, it had more impact on KAU students (284/678 (41.9\%)) compared to KSU students (44/475 (9.3\%)).

\section{Discussion}

Mandating students' attendance in classrooms has been, and continues to be a disputable issue, particularly for dental schools. Available literature on students' attendance patterns is scarce and there is no agreement between scientists about the potential impact, if any, on the academic performance of students (Alghamdi et al., 2016; Credé et al., 2010; Demir et al., 2017). A significant number of studies supported inclass attendance and demonstrated its importance for academic success. For instance, Demir et al. (2017) evaluated the academic performance of a group of $2^{\text {nd }}$ year medical students based on their attendance rate and revealed that those who attended in-class lectures had a significantly higher number of correct exam answers. Similar to the current study, Moore et al. (2008) reported the following reasons to skip in-class lectures stated by students: lecture timing, lecturer's skills and the availability of the learning material online. However, Van Walbeek (2004) supposed that the relationship between attendance compliance and better academic performance is weaker than anticipated, which was in line with Chan (2009) who revealed that at the end of the 4-month block of diagnostic radiology course there was no difference between the academic achievement of medical students who were present and absent at 6 randomly selected lectures and that classroom attendees retained knowledge only for a short period of time.

As the debate stands, classroom attendance of dental students continues to be mandatory in all schools in Saudi Arabia. However, several schools in the country reported variable absenteeism rates among dental students and proposed continuing education sessions and workshops for schools' administrations to better understand this phenomenon and suggest proper solutions. One approach was the implementation of a 
students' attendance tracking mechanism which varied among different schools. For instance, KAU adopted manual sign-in sheets before, during or after lectures to capture students' attendance. However, KSU had implemented a fingerprint tracking method for students' attendance in classrooms. Using this method, students are required to register this attendance prior to and at the end of each lecture. As such, the aim of this study is to compare dental students' attendance attitudes and patterns at KAU and KSU dental schools considering the difference in tracking daily attendance.

The current data have demonstrated that students from both KAU and KSU in general, are inclined to skip classroom lectures. However, KAU students were likely to skip more lectures compared to KSU students (3-6 Vs 0-2 lectures). This difference could be caused by several factors, such as differences in commuting time, lecture scheduling and attendance tracking methods. Due to the lack of official data on local daily traffic in the areas around both schools, the role of transportation time cannot be assessed in this report. Other factors such as lectures' day timings and individual interests in attending classroom lectures were also reported by both groups (Figure 2). However, the fact that KSU has implemented a fingerprint tracking method may have encouraged better students' attendance in classrooms to avoid academic warnings and potential suspensions or disqualification from exams which is yet to be confirmed. The available literature has discussed attendance tracking policies in fields other than dentistry. A retrospective study included medical students who spent 2.5 years at Melaka Manipal Medical College (India) and demonstrated the impact of changing attendance policy on students' GPA and absenteeism. The study reported classroom attendance rate to improve from $4 \%$ to $11 \%$ of the total number of students who never skipped classes when the school expanded its mandatory attendance from $75 \%$ to $90 \%$ of total classes (Subramaniam, Hande, \& Komattil, 2013). In addition, students' academic performances were positively related to increased attendance rate.

Other factors with an impact on dental students' attitude toward classroom attendance were addressed in this study. The students' academic performance track record is one of them as study participants from KSU had on average higher GPA compared to KAU students (68.0\% vs 55.5\%), although these GPA figures may not be totally comparable due to lack of national examination programme for all dental students. Similar outcomes were reported in a prospective study which included 126 students enrolled in different programmes at 3 South African Universities (Wadesango, 2011). This study demonstrated that students who did not attend classroom lectures had lower academic performance record compared to those who attended them. Our research is also in line with the study by Hidayat, Vansal, Kim, Sullivan and Salbu (2012) which evaluated the relationship between attendance and academic performance of 135 pharmacy school students. The study concluded that low performing students had missed more classes than their peers with higher performance records ( $34.7 \%$ vs $15 \%$ ). However, our results are contrary to those obtained by Azab et al. (2016) who failed to show a significant relationship between overall academic performance and attendance of preclinical courses by 2nd year dental students of Tuft School of Dental Medicine in Boston, MA.

The lecture timing was reported by study participants as the main reason to influence their decision to attend specific lectures at both KAU and KSU. In total, $45.3 \%$ of KSU students and $52.1 \%$ of KAU students were more likely to skip early morning classes. One explanation could be the individual lifestyles when staying up late is a common behaviour among certain groups of students. As a result, attending early classes become a challenge. In addition, poor time management and the inability to prioritise daily tasks are other factors to consider. Longer travel time was also reported by participants to impact the attendance rate of classroom lectures. In total, $10.7 \%$ of KSU students and $16.5 \%$ of KAU students had to commute for more than 60 minutes to reach their designated schools on daily basis. As such, heavy road traffic jams combined with a lack of proper time management are expected to result in more frequent tardiness or absence from classroom lectures. Similar data were reported by Monash University (Australia) for pharmacology and biochemistry students as early morning lectures were more likely to be skipped (Davis, Hodgson, \& Macaulay, 2012) This factor is more likely to be a worldwide challenge especially in heavy-populated metropolitans as in case of the cities of Jeddah (KAU) and Riyadh (KSU) and is not equally important for other students in Saudi Arabia. Time management in these settings are pivotal, and should be reinforced by faculty members and academic advisors on a regular basis. Even with the study being conducted at 2 dental schools in Saudi Arabia, variable components may still be applicable to other dental schools worldwide.

Overall, no specific pattern was noted among students of different levels in terms of classroom attendance between KAU and KSU. However, both schools have incorporated an online learning portal through Blackboard Inc ${ }^{\circledR}$ (Washington, D.C.) to provide study material for students which may have negatively affected students' attendance at both dental schools. Similar observations were reported in the literature, particularly in the study by Schnee et al (2019) which showed the decrease of students' attendance rate when lecture materials were provided via online resources. At the end of the study, students attending 
lectures earned higher grades compared to their peers who were relying on online videos only (Schnee et al., 2019).

Multiple factors with potential influence on students' attitude toward classroom attendance have been considered in this report. However, the impact of these factors on the overall academic performance has to be further investigated. This study comes at a special time of COVID-19 global outbreak which forced the closure of almost all schools around the world with concurrent switching to virtual learning and cancellation of student physical attendance in classrooms. Different types of lectures, webinars and exams were conducted via online applications such as Zoom, MicrosoftTeams and Google Hangouts to ensure delivery of knowledge and maintain the educational process, yet maintaining the safety of students and educators. A survey of a group of European dental schools has demonstrated that more than $90 \%$ have adopted online learning with limited clinical services during the time of pandemic (Quinn et al., 2020). Further recommendations included encouragements to use online resources and engagement in self-learning processes as well as providing mental health support to students and academic staff (Meng, Hua, \& Bian, 2020) In addition, formative and summative assessments were postponed and examinations had to be organised online. It is anticipated that COVID-19 outbreak will change the student learning paradigm and reveal the true potential of distant online learning to become a strategic option for educational authorities (Quinn et al., 2020). However, the efficiency of virtual learning, students' experiences and associated challenges are aspects yet to be explored and reported in the near future by researchers in the field of education.

The current data have highlighted certain aspects of attitudes and patterns of student attendance. Considering the changing world of dental education combined with the current impact of COVID-19 pandemic, in-class lectures may be a challenging option though playing an integral part of students' academic development and attainment which are less likely to be gained outside the classroom. Students who often skip classes are perhaps those who are more likely to work less, lack interest in dental subjects and may not rise to academic challenges. It can be argued that the online teaching could be a helpful tool or a coping mechanism for a particular group of students with psychological challenges, which justifies making classroom lecture attendance optional. Based on the current report, we can also conclude that the best approach to supporting students' academic performance is to combine in-class learning with the use of online resources.

This study has several limitations. Firstly, self-reported attendance may have affected the validity of this study as no official attendance records were available. It is not uncommon for students to report more favourable answers to survey questions even if not completely true to improve their academic image among school administration. Keppens et al compared self-reported and official attendance records at 57 schools in Flanders (Belgium) and indicated that students are likely to report better daily attendance than what was registered by the school administration (Keppens, Spruyt, \& Dockx, 2019). Secondly, the cross-sectional design of this study and the lack of long-term follow-up data to correlate students' attendance with their academic performance may not allow for a complete assessment of the available data. Thirdly, a comparison of several parameters between the two schools, such as GPA, was not possible due to the nature of the study and lack of national exam for all enrolled dental students. Our research group is currently planning a future study to address these limitations and attempt to analyse deeper the students' attendance records and their correlation with academic performance. In addition, the next study will explore potential solutions within focus groups.

\section{Conclusion}

The current study reported students' attitudes toward absenteeism at two governmental dental schools in Saudi Arabia with different attendance tracking methods. Reasons such as the time of lecture, commuting time and lecturers' skills were reported to influence dental students' decision to skip or be late for a classroom lecture. The current data shed light on the role of students' attendance tracking method adopted by a particular school in the encouragement of better classroom attendance and can be considered by other schools in the future based on curriculum and factors such as students' population and attitudes. Further long-term studies to understand the impact of classroom lecture absenteeism on academic performance are needed.

Conflict of Interest:

All authors declare that they have no conflict of interest related to this study. 


\section{References:}

Alghamdi A., Yamani A., Khalil A., Albarkati B., Alrehili O., Salih M. (2016). Prevalence, causes and impacts of absenteeism among medical students at UQU. Education, 6(1), 9-12. doi:10.5923/j.edu.20160601.02

Alhabi, O., Abukhelaif, A., Dokhaikh, F., Alghamdi, A., Al Ghamdi, M., \& Balkheir, M. . (2017). Absenteeism and Lateness among Saudi Medical Students at Albaha University, Saudi Arabia: An observational Study. Journal of Research \& Method in Education, 7(6), 38-41. doi: 10.9790/7388-0706053841

Azab, E., Saksena, Y., Alghanem, T., Midle, J.B., Molgaard, K., Albright, S., Karimbux, N. (2016). Relationship Among Dental Students' Class Lecture Attendance, Use of Online Resources, and Performance. J Dent Educ, 80(4),452-8. doi: 10.1002/j.0022-0337.2016.80.4.tb06103.x

Cook, D. A. (2005). The research we still are not doing: an agenda for the study of computer-based learning. Acad Med, 80(6), 541548. doi:10.1097/00001888-200506000-00005

Credé, M., Roch, S., \& Kieszczynka, U. (2010). Class Attendance in College. Review Of Educational Research, 80(2), $2772-2295$. doi: $10.3102 / 0034654310362998$

Davis, E. A., Hodgson, Y., \& Macaulay, J. O. (2012). Engagement of students with lectures in biochemistry and pharmacology. Biochem Mol Biol Educ, 40(5), 300-309. doi:10.1002/bmb.20627

Demir, E. A., Tutuk, O., Dogan, H., Egeli, D., \& Tumer, C. (2017). Lecture attendance improves success in medical physiology. Adv Physiol Educ, 41(4), 599-603. doi:10.1152/advan.00119.2017

Desalegn, A. A., Berhan, A., \& Berhan, Y. (2014). Absenteeism among medical and health science undergraduate students at Hawassa University, Ethiopia. BMC Med Educ, 14, 81. doi:10.1186/1472-6920-14-81

Hidayat, L., Vansal S., Kim, E., Sullivan, M. \& Salbu, R. (2012). Pharmacy Student Absenteeism and Academic Performance. American Journal of Pharmaceutical Education, 76 (1) 8. doi:10.5688/ajpe7618

Keppens, G., Spruyt, B., \& Dockx, J. (2019). Measuring School Absenteeism: Administrative Attendance Data Collected by Schools Differ From Self-Reports in Systematic Ways. Front Psychol, 10, 2623. doi:10.3389/fpsyg.2019.02623

Massingham P, H. T. (2006). Does attendance matter? An examination of student attitudes, participation, performance and attendance. J Univ Teach Learn Pract., 3(2), 83-103. https://files.eric.ed.gov/fulltext/EJ1105382.pdf

Meng, L., Hua, F., \& Bian, Z. (2020). Coronavirus Disease 2019 (COVID-19): Emerging and Future Challenges for Dental and Oral Medicine. J Dent Res, 99(5), 481-487. doi:10.1177/0022034520914246

Moore, S., Armstrong, C., \& Pearson, J. (2008). Lecture absenteeism among students in higher education: a valuable route to understanding student motivation. Journal of Higher Education Policy and Management, 30(1), 15-24. doi:10.1080/13600800701457848

Quinn, B., Field, J., Gorter, R., Akota, I., Manzanares, M. C., Paganelli, C., . . . Tubert-Jeannin, S. (2020). COVID-19: The immediate response of european academic dental institutions and future implications for dental education. Eur J Dent Educ. doi:10.1111/eje.12542

Schnee, D., Ward, T., Philips, E., Torkos, S., Mullakary, J., Tataronis, G., \& Felix-Getzik, E. (2019). Effect of Live Attendance and Video Capture Viewing on Student Examination Performance. Am J Pharm Educ, 83(6), 6897. doi:10.5688/ajpe6897

Stewart, M., Stott, T., \& Nuttall, A.-M. (2011). Student Engagement Patterns over the Duration of Level 1 and Level 3 Geography Modules: Influences on Student Attendance, Performance and Use of Online Resources. Journal of Geography in Higher Education, 35(1), 47-65. doi:10.1080/03098265.2010.498880

Subramaniam, B., Hande, S., \& Komattil, R. (2013). Attendance and achievement in medicine: investigating the impact of attendance policies on academic performance of medical students. Ann Med Health Sci Res, 3(2), 202-205. doi:10.4103/21419248.113662

von Elm, E., Altman, D. G., Egger, M., Pocock, S. J., Gotzsche, P. C., Vandenbroucke, J. P., \& Initiative, S. (2008). The Strengthening the Reporting of Observational Studies in Epidemiology (STROBE) statement: guidelines for reporting observational studies. J Clin Epidemiol, 61(4), 344-349. doi:10.1016/j.jclinepi.2007.11.008

Received: December 26, 2020 Accepted: April 21, 2021 